\title{
VASCULAR ANATOMY OF ANGIOPTERIS EVECTA
}

CONTRIBUTIONS FROM THE HULL BOTANICAL LABORATORY 290

H U G O L. B L O M Q IS T

(WITH PLATES V-VIII AND EIGHT FIGURES)

In the study of the vascular anatomy of plants it has been realized that it is necessary to study the successive stages which the plant passes through in the progress of its development. Since it is the aim, first of all, to determine the position, interrelationship, and structure of the different vascular components of the mature plant, this procedure not only facilitates the work, but in most cases perhaps is, absolutely necessary. Likewise, in the search for facts which are to show indications of phylogenetic relationship, it is unnecessary to point out that it is in the developmental stages that these are most likely to be found. This method has proved to be especially necessary in the case of the Marattiaceae, for the vascular structures in the mature plant are not only very complex and difficult to interpret, but as the plant develops there are marked changes appearing in the anatomical structures from stage to stage. In some of the previous investigations on the anatomy of the Marattiaceae the failure to follow this method has led to much confusion and incorrect interpretation of the facts.

\section{Historical}

Considerable attention has been given to the Marattiaceae in the last fifty years, due chiefly to the evidence from geological records that this group of ferns, or a closely related group, was of great abundance and wide distribution in the past, and to the unique morphological and anatomical features which this group presents. Most of the work done on the anatomy of the Marattiaceae has been rather scattered and incomplete. The reason for this has chiefly been the lack of material, as these ferns are restricted to rather inaccessible parts of the world. Although plants have been transported to many conservatories, this has not I8r]

[Botanical Gazette, vol. 73 
appreciably altered the situation, because of the tardiness in the germination of spores and the slowness of growth of the gametophyte.

The investigations on the anatomy of the Marattiaceae up to I900 have been reviewed by Miss Shove (I2). It is evident that the work up to that time was rather unsatisfactory, as only mature stems were dealt with, and the material in most cases was limited to one specimen. Miss Shove also worked with a mature stem. Since then, however, several invest gations have been carried out in which the younger stages have been studied. In I902 FARMER and Hull (8) published the results of an investigation on the development of the vascular anatomy in Angiopteris evecta, which was supplemented by a paper on the younger stages by CAMPBELL (2) in 1909. A thorough investigation on the development of the vascular anatomy of Marattia alata was carried out by Miss Charles (7) in r9i . This was the first investigation on the anatomy of this group based on an abundance of material. In I9I7 WEST (r3) added another contribution to the knowledge of the vascular anatomy of this group in a paper on the anatomical structures of Danaea spp. and several of the other genera. This investigation also was based on an abundance of material.

In comparing the conclusions drawn in this literature, it is evident that the vascular anatomy of the plants of the six genera of the Marattiaceae is very complex, but shows a striking similarity in facts both in the developmental stages and the more mature plants. Differences which are reported are mainly in details and in the interpretation of facts. There seems to be an agreement of opinion that the sporophyte of the Marattiaceae is traversed by a central strand of vascular tissue, called a dictyostele, from which roots and leaf traces arise. This stele is at first solid, or protostelic, then passes to a more or less tubular form, a solenostele, which is soon broken open by leaf gaps which are at first wholly repaired, but later overlap, so that the central strand becomes a banded structure which appears crescent-shaped in cross-section. This at first is simple, but later becomes complicated by the appearance of commissural and medullary strands. Disagreement is shown in regard to the meristematic regions, the 
presence or absence of an endodermis, the origin of lateral roots, and whether the central strand is of cauline or foliar origin. The relationship between roots and leaves and the vascular arrangements in the stipules are also points still unsettled.

\section{Material and methods}

The material used in this investigation was collected on the island of Tutuila, Samoa, by Dr. W. J. G. LAND, of the Hull Botanical Laboratory, during October and November i9r 2. It consisted of an abundance of young sporophytes of Angiopteris evecta, ranging from the first to the tenth leaf stages and a few somewhat more advanced.

This material was imbedded in paraffin, and complete serial sections ranging from to to $20 \mu$ in thickness were made with a rotary microtome. These sections were then studied from below upward, and diagrammatic reconstructions were drawn of the different stages. From these a final reconstruction was made in which the different stages were superposed one upon another to show as clearly as possible the successive stages which the plant passes through in the progress of its development. The most serious difficulty encountered was the fact that as the sporeling develops beyond the third and fourth stages, the lower part of the stem becomes more or less distorted, and in still older stages even decays. This difficulty was overcome by studying a close series of stages, which the material provided, selecting characteristic sections from the younger stages, and carefully matching these with sections representing the same morphological location in the older stages. The possibility of misinterpretation due to local variations, which are quite common in the anatomy of Angiopteris, was guarded against by studying several specimens of the same or approximately the same stage.

\section{Investigation}

\section{EXTERNAL FEATURES}

While the external features of Angiopteris have been described by several investigators, these will be reviewed in part to assist in relating the internal structures with the external features. The 
first peculiarity of the young sporophyte of Angiopteris, as well as of all Marattiaceae, is the way in which the first leaf makes its exit from the gametophyte. As is well known, in most ferns the primary leaf grows first downward, and then emerges from under the gametophyte through the notch in the heart-shaped form of the latter. In Angiopteris, on the contrary, the first leaf pushes its way upward through the gametophyte and emerges on the dorsal side, as shown in figs. I and 2. CAmpbell (3) attributes this behavior to the fact that the first division of the fertilized egg comes
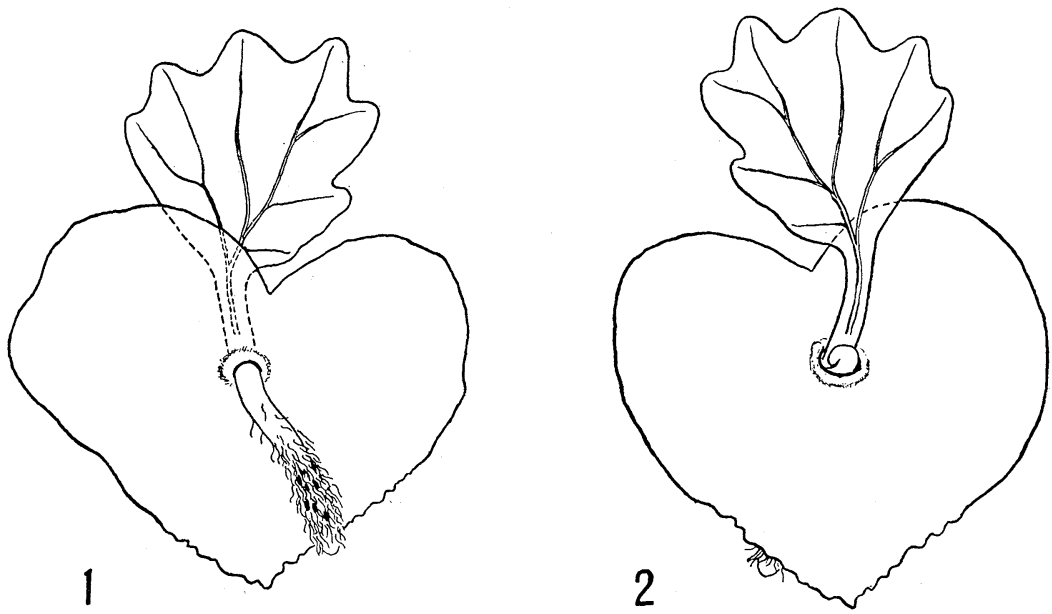

FIGS. I, 2.-Gametophyte and sporeling of Angiopteris, showing mode of exit of primary sporophyte organs from prothallus; $\times_{4}$.

in transversely to the axis of the archegonium, or parallel with the axis of the gametophyte; while in most ferns it is usual to find the first wall perpendicular to the gametophyte, or parallel with the axis of the archegonium. In an unpublished paper by LAND (II) on the embryogeny of Angiopteris, the presence of a well defined suspensor is reported, and he suggests that this organ very probably is responsible for the initial upward growth of the primary leaf in the Marattiaceae. The suspensor has now been reported for two other genera, Macroglossum (5) and Danaea (I), and it is probable that its presence in the remaining genera awaits further investigations. 
The next point to be observed is the appearance of the stem tip. About the time the first leaf has emerged from the gametophyte, a slight depression is seen on the dorsal side of the petiole where this passes into the root. At the bottom of this depression there is a well defined apical cell, which can easily be seen from longitudinal sections of the young sporophyte. The second leaf appears on the crest of this depression, usually about $130^{\circ}$ from the first, while the corresponding root emerges directly below, next to the primary root. The succeeding leaves appear at approximately the same distance from the next older leaf that the second appeared from the first, thus forming a spiral arrangement which may be clockwise in one plant and counter-clockwise in another. This habit has an important bearing upon the development of the internal structure, as will be shown later. The succeeding roots grow through the cortex and appear from below the thickening stem, and later penetrate the sides. The relation between the roots and the corresponding leaves cannot be determined from external appearances after the third and fourth leaves have appeared. In none of the specimens studied had the roots branched, and no differences, except in size, could be discerned from the external appearances of the different roots.

A characteristic feature of the mature plants of the Marattiaceae is the presence of conspicuous fleshy stipules. In the first leaf of Angiopteris no stipules are visible, while in the second slight thickenings show their rudiments. No well developed stipules appear until the fourth leaf. At this stage the stipules appear as lateral swellings on the petiole as soon as the leaf is visible. As the leaf develops and the petiole elongates, the upper part of the stipule splits away from the petiole, and this gives rise to the more or less pointed lobes. In all sporelings examined there were no indications of dorsiventrality, either in external appearance or internal structure.

\section{GENERAL INTERNAL STRUCTURE}

The general internal structure of a stem of Angiopteris which has developed beyond the first few stages may be divided into two main regions, the cortical and the central vascular. The cortex, 
which is composed of rather large, thin-walled cells without intercellular spaces, is relatively thick, with an abundance of starch deposited in the cells surrounding the central region. In the younger stems cells filled with tannin are quite abundant, but in the older stages these are less common. This cortical area is traversed by the outgoing leaf traces, and numerous roots digest their way down through it. The leaf traces are single in the younger stages, but in the older levels these bifurcate before entering the stipules. Because of the spiral arrangement of the leaves, the leaf traces are arranged in zones which exhibit a spiral appearance in crosssection, in which the younger are closer to the center than the older. No fusing of leaf traces or a branch from one leaf trace with that of another takes place. The leaf traces pass outward directly.

The central region consists of the vascular tissue, imbedded in a ground tissue which may be called the central parenchyma. This parenchyma does not differ markedly from the cortical tissue except that the cells are somewhat smaller, have thinner walls, and less starch. In the first few stages there is a conspicuous endodermis, but in the older stages there is no such layer of cells which marks off the central region from the cortex, and the central parenchyma passes insensibly into the former. The central vascular tissue consists of a strand which appears more or less crescentshaped in cross-section. The xylem is endarch and is completely surrounded by phloem. From one edge of this strand leaf traces are given off, and this contribution is always from the same edge in the same plant (figs. 3,4). On the outer side of the other edge of this central strand a root stele is joined, usually at about the same level that the leaf trace is given off. The vascular tissue thus contributed to the leaf traces is made good on the other edge in two ways, by an increase of vascular tissue on the edge itself and by the addition of commissural strands. From the edge of each leaf trace abutting on the opening in the central strand a commissural strand is given off where the leaf trace is freeing itself from the central strand. This bends outward and passes diagonally upward and fuses with the opposite edge of the central strand just below where the next root above is attached (figs. 9-15). 


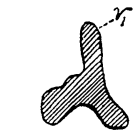

$A$

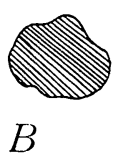

$B$

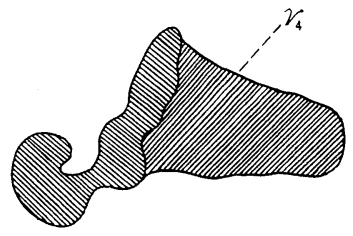

F
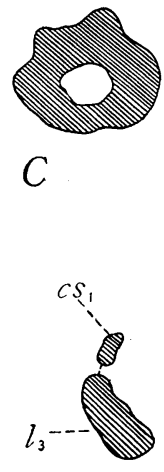

G
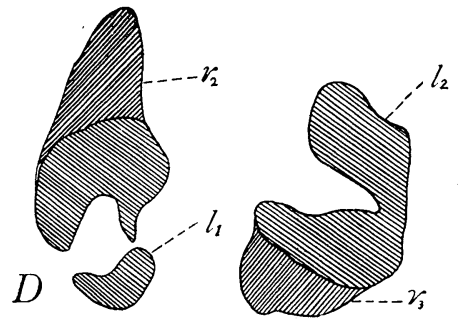

$E$

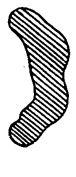

Fig. 3.-Diagrams of sections of stele, showing stele development up to third leaf (only xylem shown); sections not successive: $r_{\mathrm{x}}, r_{2}, r_{3}, r_{4}$, first, second third, and fourth root traces; $l_{\mathrm{I}}, l_{2}, l_{3}$, first, second, and third leaf traces; $c s_{\mathrm{I}}$, first commissural strand; $X_{\mathrm{I} 76}$.
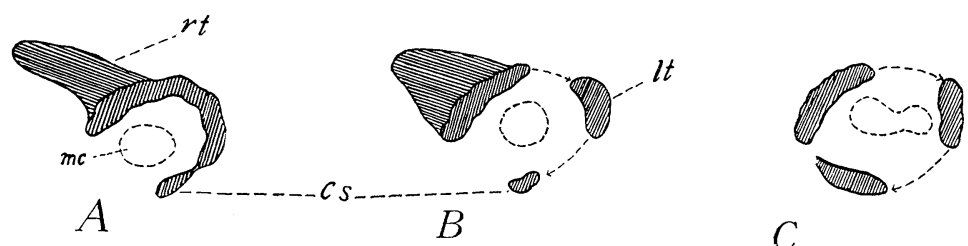

C
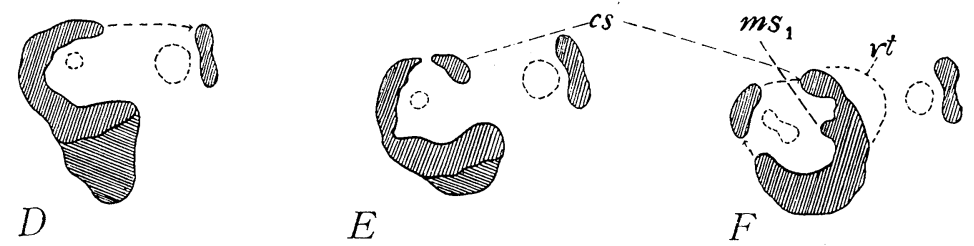

FIG. 4.-Diagrams of sections of stele, commencing slightly below where first medullary strand appears (only xylem shown); sections not successive: $r t$, root stele; $c s$, commissural strand; $l t$, leaf trace; $m c$, mucilage canal; $m s_{\mathrm{I}}$, first medullary strand; $\times 80$. 
It is evident that by a continual loss of tissue from one edge and an addition on the other, in the successive sections, the crescents will appear to move in a circle, indicating that the strand is a more or less open spiral. The explanation for this spiral condition is to be found in the spiral succession of the leaves. In the stages above the eighth leaf, a medullary strand appears on the inner side of the central strand, usually slightly above and opposite the junction of a root stele. This passes diagonally upward, crosses the central parenchyma tissue, and fuses with the commissural strand before the latter has joined the central strand (fig. 5). In this condition they meet the edge of the central strand, and the commissural strand fuses with the latter and is lost. The medullary strand, fused to the inner side of the central strand, but retaining its identity, passes upward until the union of the root and the central strand has been cleared, when it frees itself and repeats its course across the central parenchyma tissue. This behavior of the medullary strand agrees in the main with the condition in Marattia as described by Miss Charles (7). In the lower levels of the stem a mucilage canal appears in the center of the parenchyma tissue. This canal divides wherever a leaf trace is given off, and one of the branches follows the inner side of the latter.

Each leaf trace is definitely related to one root. Holle (Io) has reported the same condition in Marattia, but found two roots to each leaf in Angiopteris. The writer in some cases found two roots attached on the same level, and it appeared as if two roots were related to one leaf. After following out the series, however, it was found that these roots were related to different leaves. This variation will be discussed more fully later. The root which appears almost opposite each leaf trace is related to the next leaf above. In the younger stages each leaf trace is joined to the central strand directly above the insertion of its corresponding root (fig. 9); but in the older stages the leaf trace may be displaced to the right or left of the corresponding root, as the case may be, due to the spiral condition of the central strand (figs. II-I5). The distance between the root stele and the junction of the corresponding leaf trace above increases also in the successive stages. 

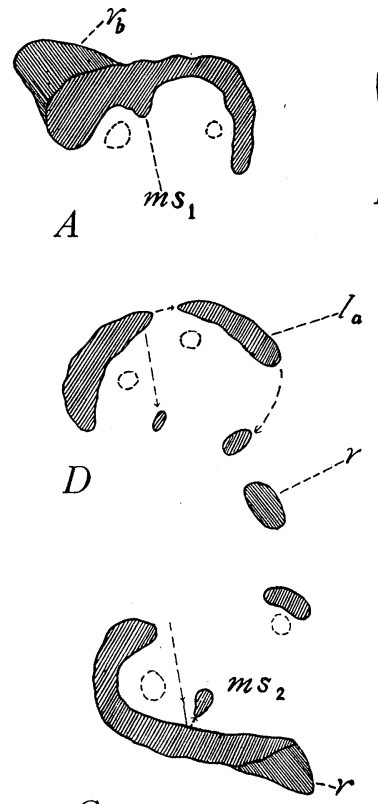

$G$
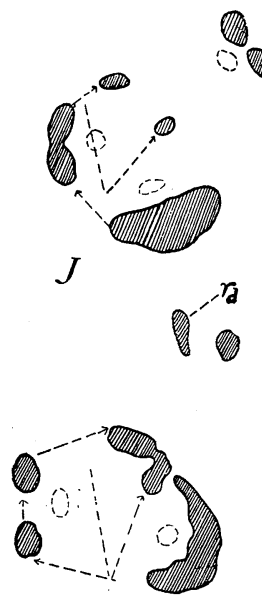

$M$
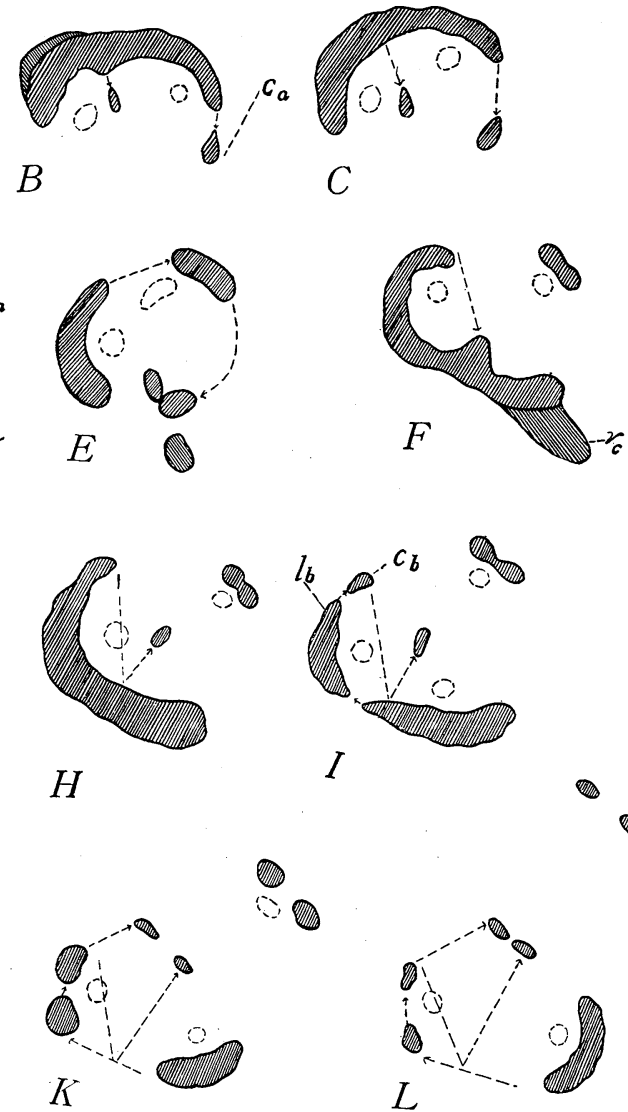

-
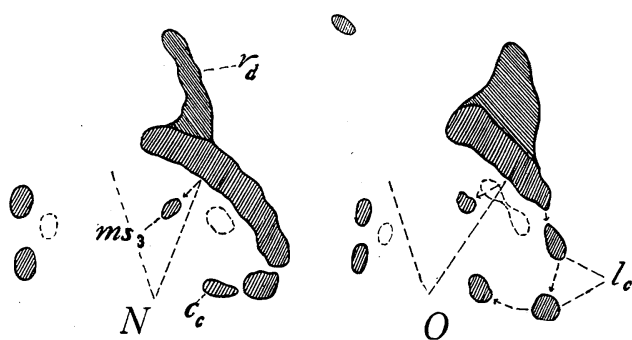

Fig. 5.-Diagrams of sections of stele, showing course of different vascular components after appearance of medullary strand (only xylem shown); sections not successive: $r$, root stele; $l$, leaf trace; $m s$, medullary strand; $c$, commissural strand; $m c$, mucilage canal; dotted lines with arrows indicate origin; and approximate courses of leaf traces, commissural strands, and medullary strand; $\mathrm{X}_{\mathrm{I}} 6$. 


\section{First LeAF STAGE}

The first few stages have been described by FARMER (8) and CAmpbell (2), and the present investigation adds little to their descriptions. The primary root is stated by them to be diarch. The writer found this to be true in some cases, but in as many cases the root was found to be triarch. Similar variations have been reported by CAMPBELL in Danaea, Botrychium, and Helminthostachys (3). The endodermis is well organized and is separated from the protoxylem and protophloem by a uniseriate pericycle. In some places the protoxylem abuts directly on the endodermis, as has been reported previously (8). In the diarch stele there are two protophloem points and in the triarch three (figs. I6, I7).

The transition region in Angiopteris, as reported for other Marattiaceae, is a solid strand of vascular tissue with more or less irregular outl'ne (fig. I9). In passing from this region upward, some cells in the xylem remain unlignified, usually near the center of the stele, so that the latter may become more or less tubular in cross-section. This condition has been called a solenostele (fig. 25). In some cases, however, these parenchyma cells are more scattered, and the condition resembles what has been reported for Danaea by BREBNER (I). In this genus the parenchyma cells appear without any relation to the center of the protostele. In either case the appearance of these unlignified cells marks the union of the next root stele and the corresponding leaf trace above. The writer agrees with BREBNER that "the parenchyma ... called pith is probably simply due to the root-junction and the preparation of the departure of the leaf trace." No phloem is developed in the center of the tubular stele at this stage.

A longitudinal section of the sporeling at this stage shows a well defined apical cell at the stem tip (fig. r8). This apical cell has been reported by CAMpBELL in Macroglossum (5), by Miss Charles in Marattia (7), and by West in Danaea (13). In a transverse section it was impossible to locate definitely this apical cell, but from the shape of the cells in the stem tip region it seems that this cell is four-sided. No procambial tissue is to be observed below the stem tip, a condition which has been reported by BREBNER for Danaea and by CAMPBELL for Angiopteris. The first differentia- 
tion of vascular tissue is found to be related to the second leaf trace. The few tracheids which join up the first leaf stage with the second pass into the second root stele, while some pass directly upward and add to the structure of the second leaf trace (fig. $3 D, E$ ).

\section{SECOND LEAF STAGE}

The second root appears slightly above the transition region, about $130^{\circ}$ from the first leaf trace. Fig. 20 shows this root in a very young stage. It is impossible to state from what tissue this originates, since it appears before any differentiation of tissues has taken place. The same is also true of Marattia. The second leaf trace appears directly above the second root. Some variation occurs at this stage; the second leaf trace may be joined to the third by both edges, in which a second tube is formed and the gap formed by the first leaf is repaired. In as many cases, however, only one edge is joined up with the third leaf trace, and in such cases the leaf gap is not repaired. In either case the phloem occurs on the inside as well as on the outside of the vascular tissue. The endodermis which was very evident in the first stage is more difficult to locate. Although endodermal thickenings occur, the characteristic organization is more or less broken up. In no cases was the vascular tissue observed to become a solid strand after the junction of the first and second leaf stages had been passed. In Marattia, on the contrary, the protostelic condition may appear more than once.

\section{THIRD LEAF STAGE}

After the second leaf stage has been passed, the vascular tissue of the central region never appears as a tube. The third root stele originates on the level with the outgoing of the second leaf trace from the central region. At this stage the leaf trace comes off from one edge of the central strand, which is the vascular tissue leading up to the fourth leaf trace (fig. $3 F-H$ ). The latter tissue now assumes a crescent-shaped form in cross-section. A few scattered tracheids may come off the free edge of the third leaf trace and wander back toward the central strand, or may end blindly before arriving there. These tracheids represent the rudimentary commissural strand, which in many cases is fairly 
well developed at this stage (fig. $3 G, H$ ). The leaf trace passes out to the petiole undivided, and the stipules, which are not conspicuous at this stage, have no vascular strands.

\section{FOURTH AND FIFTH LEAF STAGES}

In the fourth leaf stage the commissural strand is well developed and separates from the leaf trace after the latter has passed a considerable distance from the central strand, then it approaches the opposite edge of the latter. This behavior is the same as shown in fig. $4 A-C$. Meanwhile this edge of the central strand is approaching the commissural strand by the addition of vascular tissues, and when the two meet, fusion takes place (fig. $4 C-F$ ). At this stage a mucilage canal appears in the center of the central parenchyma. This divides where the leaf trace goes outward, and one branch follows the inner side of the trace. The fifth stage is very much like the fourth except that the strands are larger and the commissural strand leaves the leaf trace closer to where the latter comes off the central strand. The central strand has increased in size so that the root stele reaches only half way around the other side. No well defined endodermis is discernible in this and the subsequent stages.

\section{SiXTh AND SEVENTH LEAF STAGES}

The sixth and seventh leaf stages differ from the fifth mainly in the stipular region, which will be discussed later.

\section{EIGHTH AND NINTH LEAF STAGES}

In the eighth leaf stage a new feature presents itself in the appearance of a medullary strand. This strand is first visible coming off the inner side of the central strand opposite the junction of the ninth root (fig. ${ }_{4} F$ ). The medullary strand takes a diagonally upward course, crosses the central parenchyma, and fuses only partially with the commissural strand immediately before the latter has met the central strand. Both join the edge of the central strand just below the junction of the tenth root (fig. $5 A-F$ ). The commissural strand becomes an integral part of the central strand, but the medullary strand remains visible, joined to the inner side of the central strand, and passes upward to the upper level of the 
root junction (fig. I4). In these stages the leaf trace bifurcates while still within the cortex.

\section{TENTH AND SUBSEQUENT STAGES}

The tenth stage is very similar to the eighth and ninth, except that the different strands have increased in size. In cross-section the crescent shape of the central strand is less evident, especially

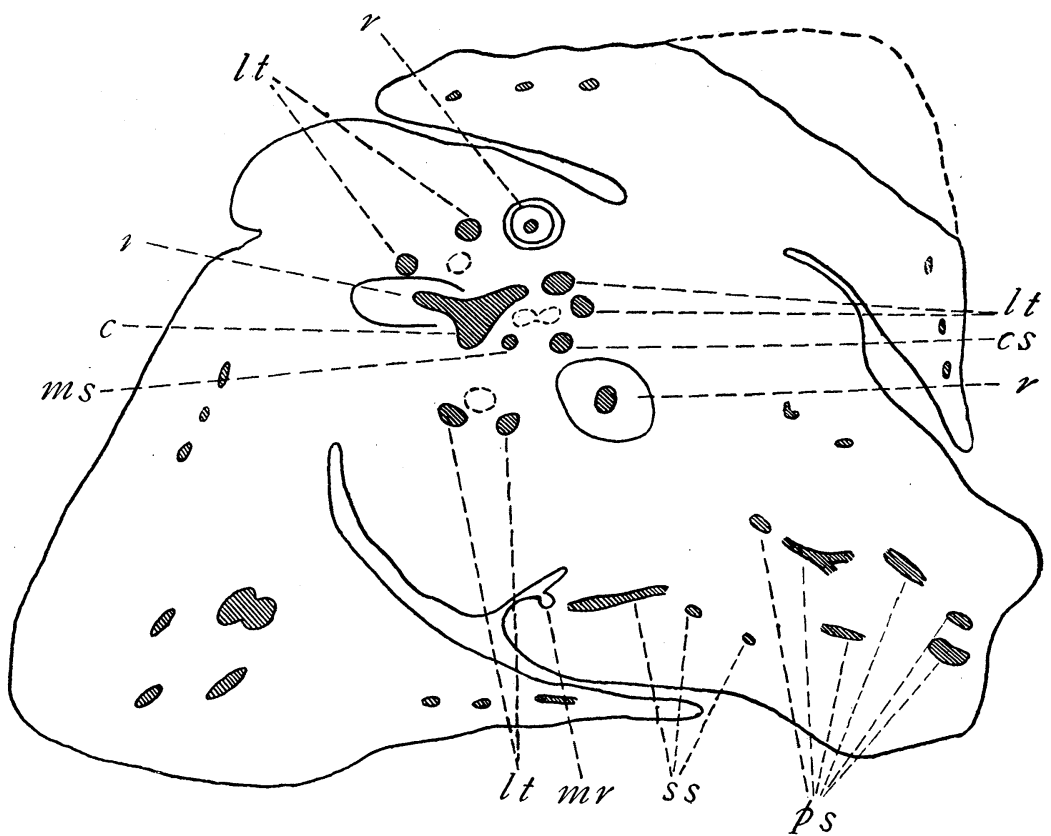

Fig. 6.-Diagram of section of stem above tenth leaf stage: $c$, central strand; $m s$, medullary strand; $c s$, commissural strand; $l t$, leaf trace; $s s$, stipular strands; $p s$, petiolar strands; $r$, root; $m r$, meristematic region of stipule; $\times 8$.

in the region of a root junction. In some places the commissural strand and the central strand are very similar both in size and shape. The central and the commissural strands and the leaf traces are always endarch, while the medullary strand is exarch (figs. 21, 22). The commissural strand comes off close to the central strand, and the leaf trace bifucates close to the central region. At this and the subsequent stages five vascular strands may leave the central strand approximately on the same level; namely, the eighth leaf 
trace (which usually comes off divided), a root stele, the commissural strand, and the medullary strand. A section of the sporophyte at this stage is shown in fig. 6 .

In the more advanced specimens studied the exact stage could no longer be determined, owing to the distortion and decay of the lower regions. The difference between these and the previous stages was shown in the earlier bifurcation of the leaf traces, which may take place as the leaf is preparing to leave the central strand.

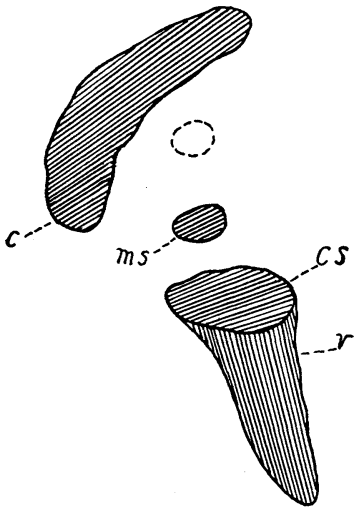

FIG. 7
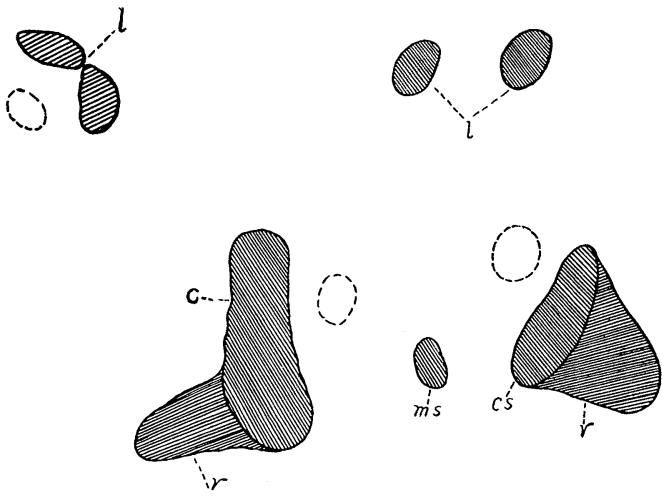

FIG. 8

FIGS. 7, 8.-Fig. 7, diagram showing root attachment to commissural strand before latter has joined central strand (only xylem shown); $c$, central strand; $m s$, medullary strand; $c s$, commissural strand; $r$, root stele; $l$, dividing leaf trace; $\times{ }_{3} 8$; fig. 8, diagram showing two roots on same level; one joined on central strand and other on commissural strand: $c$, central strand; $m s$, medullary strand; $c s$, commissural strand; $r$, root stele; $l$, bifurcated leaf trace; $\times 38$.

The commissural strand also appears earlier, in some cases before the leaf trace is free. The two branches of the leaf trace bifurcate while within the cortex, so that here four strands from one leaf trace enter the stipular region. Considerable variation was observed in the attachment of the commissural strand. This may run up farther before merging with the central strand, and the root which is usually attached to the central strand may be inserted on the commissural strand (fig. 7). In some cases also a root may appear higher on the central strand, bringing two roots almost on the same level (fig. 8). In such cases apparently the two roots are related to one leaf trace. In following out the series, however, it was found that 
the root appearing on the central strand was related to the next leaf above, while the one attached to the commissural strand corresponds to the leaf trace above that. The appearance of roots on the commissural strand seems to be a common occurrence in the older stems.

\section{VASCULAR ANATOMY OF STIPULES}

As has already been mentioned, no conspicuous stipules appear until the fourth leaf. At this stage the leaf trace passes through the stipules as a single strand, to which two weakly developed xylem strands are attached, which pass to the stipular lobes. In the fifth leaf these strands are better developed, and the leaf trace shows signs of forking where the stipular strands are attached. The latter remain unbranched for some distance from the leaf trace, when each gives off usually two branches to the upper part of the lobes. In the sixth leaf the trace forks where the stipular strands are given off, but anastomosing takes place immediately beyond. In the seventh leaf the point of forking of the leaf trace has moved closer to the stem, and anastomosing is delayed longer than in the previous stage. Further branching has taken place in the stipular strands. In the subsequent leaves the point of forking of the leaf trace moves closer and closer to the central region, until finally this takes place as the leaf trace is preparing to free itself from the central strand. Likewise, the point of anastomosing of the branches is moved farther and farther away from the point of attachment of the stipular strands, until the leaf trace passes into the petiole still divided. Above the tenth leaf the two branches from the forked leaf trace bifurcate, so that four strands enter the stipular region. In this region further branching and anastomosing take place. The course of the vascular bundles above the tenth leaf is represented in the reconstruction in fig. 34 .

The stipular strands which pass to the lobes of the stipule bend outward and pass to within a short distance of the epidermis, where they end blindly. The lowest (or the main strand), however, is terminated by a procambial strand which originates from a group of meristematic cells on the inner side of the edge of the stipule slightly above where this merges with the cortex. This meriste- 
matic region was first visible in the seventh leaf (figs. 23, 3I, 34). Such a region has been reported by GwYNnE-VAUGHAN (9) to occur in Kaulfussia andArchangiopteris, and WEST (13) reports the same for two species of Danaea. Although not reported for the other genera of the Marattiaceae, it is probable that this region is found in them also. Gwynne-Vaughan suggests that this region might represent the rudiments of the adventitious buds, and WEST reports that this does actually occur in Danaea nodosa. While this region may give rise to adventitious shoots, it seems probable that its principal function is to build up the fleshy stipules. In none of the specimens of Angiopteris studied was there any evidence of the presence of adventitious buds in this region.

\section{Conclusions}

It is evident that Angiopteris presents an example of striking general variation in the vascular structures from stage to stage. How far this variation is continued remains to be determined from further studies of more advanced stages than have been dealt with in this investigation. From the facts observed in the stages studied, however, it seems probable that some of these variations are continued indefinitely as the plant increases in size and age. The most conspicuous of these variations are: (I) the elimination of the endodermis, (2) the appearance of commissural and medullary strands and the increase in their importance in the structure of the central region, (3) the repeated bifurcation of the leaf traces, (4) the placing closer to the central strand the point of attachment of the commissural strand and the point of forking of the leaf trace, and (5) the variation in the place of attachment of the root steles. Much of this variation tends to the breaking up of the central strand, a fact which points to a polystelic condition so characteristic of the phylogenetically advanced types of the different groups of vascular plants.

The total absence of a cauline procambium is interesting, as it suggests that the central vascular structure in the stem of the Marattiaceae, and perhaps other closely related ferns, is mostly if not wholly of foliar origin; that is, it consists of a sympodium of leaf traces. The definite relation between roots and leaves strongly supports this theory. 


\section{Summary}

I. The general internal structure of the stem of Angiopteris evecta consists of two main regions, the cortical and central vascular. The relatively thick cortex is traversed by leaf traces and roots. The central region consists of a vascular strand which appears crescent-shaped in cross-section and is imbedded in a central parenchyma tissue. This strand gives off root steles and leaf traces. In addition, commissural and medullary strands appear in the central region.

2. The leaf traces are given off from one edge of the central strand, and this contribution is always from the same edge in the same plant. On about the same level that the leaf trace leaves the central strand a root is attached on the outer side of the other edge. The contribution thus made to the leaf traces is made good on the opposite edge in two ways, by an increase in the vascular tissue on the edge itself, and by the addition of commissural strands.

3. The commissural strand originates from the free edge of the leaf trace after the latter is freed from the central strand, and passes to the opposite edge of the central strand and fuses with it.

4. By a continual loss of tissue from one edge and an addition on the other the central strand assumes a spiral condition. This condition is due to the spiral succession of leaves.

5. In the older stages a medullary strand appears on the inner side of the central strand opposite the upper level of a root junction. This crosses the central parenchyma tissue and fuses with the commissural strand before the latter has fused with the central strand. After fusion has taken place, the medullary strand passes upward on the inner side of the central strand, fused to the latter but retaining its identity, until the root junction has been cleared, when it frees itself and repeats its course across the central parenchyma.

6. Each leaf trace is definitely related to one root. The root which appears almost opposite a leaf trace corresponds to the next leaf above. In the early stages each leaf trace appears directly above its corresponding root; but in the later stages the leaf trace is displaced to the right or left, as the case may be, of its corresponding root, due to the spiral condition of the central strand. 
7. The leaf traces at first are single, but later bifurcate in the stipular region, but anastomose beyond. The point of forking moves closer and closer to the central strand. Further forking and anastomosing of the leaf trace take place in the more advanced stages.

8. One strand from each side of the leaf trace goes to the lobes of the stipule. Branches from this strand supply the stipular lobes with vascular tissue.

9. All the stipular strands end blindly except the lowest or main strand, which is terminated by a procambial strand originating from a group of meristematic cells on the inner side of the edge of the stipule. This group of cells probably helps to build up the fleshy stipule.

Io. The absence of cauline procambium and the definite relation between roots and leaves suggest that the vascular tissue of the central region is a sympodium of leaf traces, and most if not all of the central strand is of foliar origin.

The writer wishes to express his gratitude to Dr. W. J. G. LAND for the valuable collection of material furnished for this investigation and for his advice, criticism, and encouragement during the progress of the work.

Trinity COLlege

Durham, N.C.

\section{LITERATURE CITED}

I. Brebner, G., On the anatomy of Danaea and other Marattiaceae. Ann. Botany 16:517-552. pls. 22, 23. 1902 .

2. CAMPBELL, D. H., The embryo and young sporophyte of Angiopteris and Kaulfussia. Ann. Jard. Bot. Buitenzorg 3:69-82. г9го.

3. - The eusporagiate ferns. Carnegie Publ. r40. r9ı r.

4. - The prothallium and embryo of Danaea. Preliminary note. Ann. Botany 23:69r. 1909.

5. - The structures and affinities of Macroglossum alidae Copeland. Ann. Botany 28:65I-669. pls. 46-48. I9I4.

6. - The eusporangiate ferns and the stelar theory. Amer. Jour. Bot. 8:303-3I5. I921.

7. Charles, Grace, The anatomy of the sporelings of Marattia alata. Bot. Gaz. 5i:8I-tor. igi I.

8. Farmek, J. B., and Hill, T. G., On the arrangement and structure of the vascular strands in Angiopteris evecta and some other Marattiaceae. Ann. Botany 16:37I-402. pls. I6-I8. 1902. 

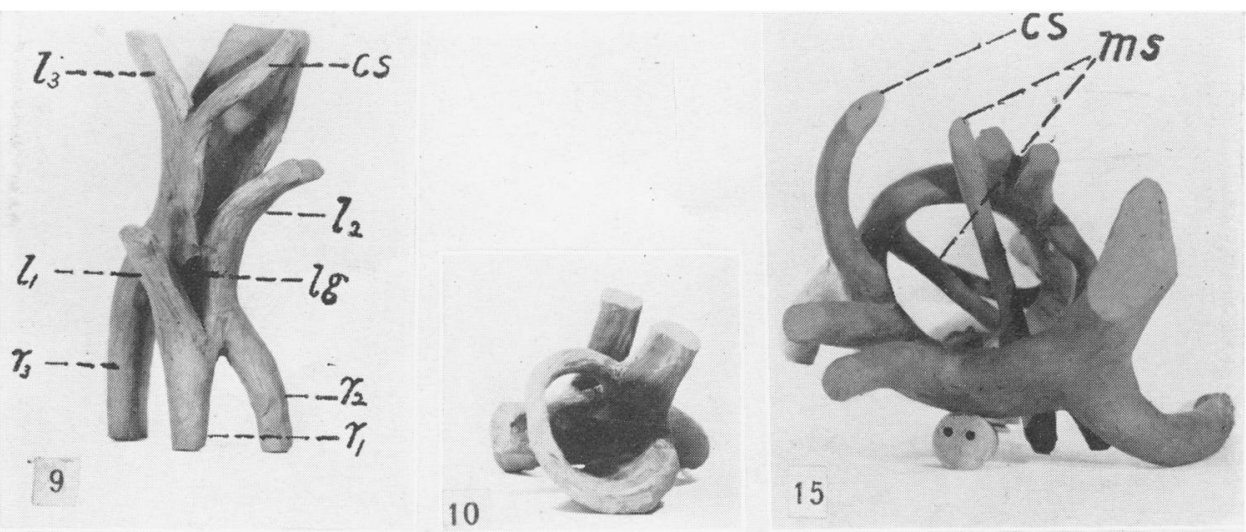

15
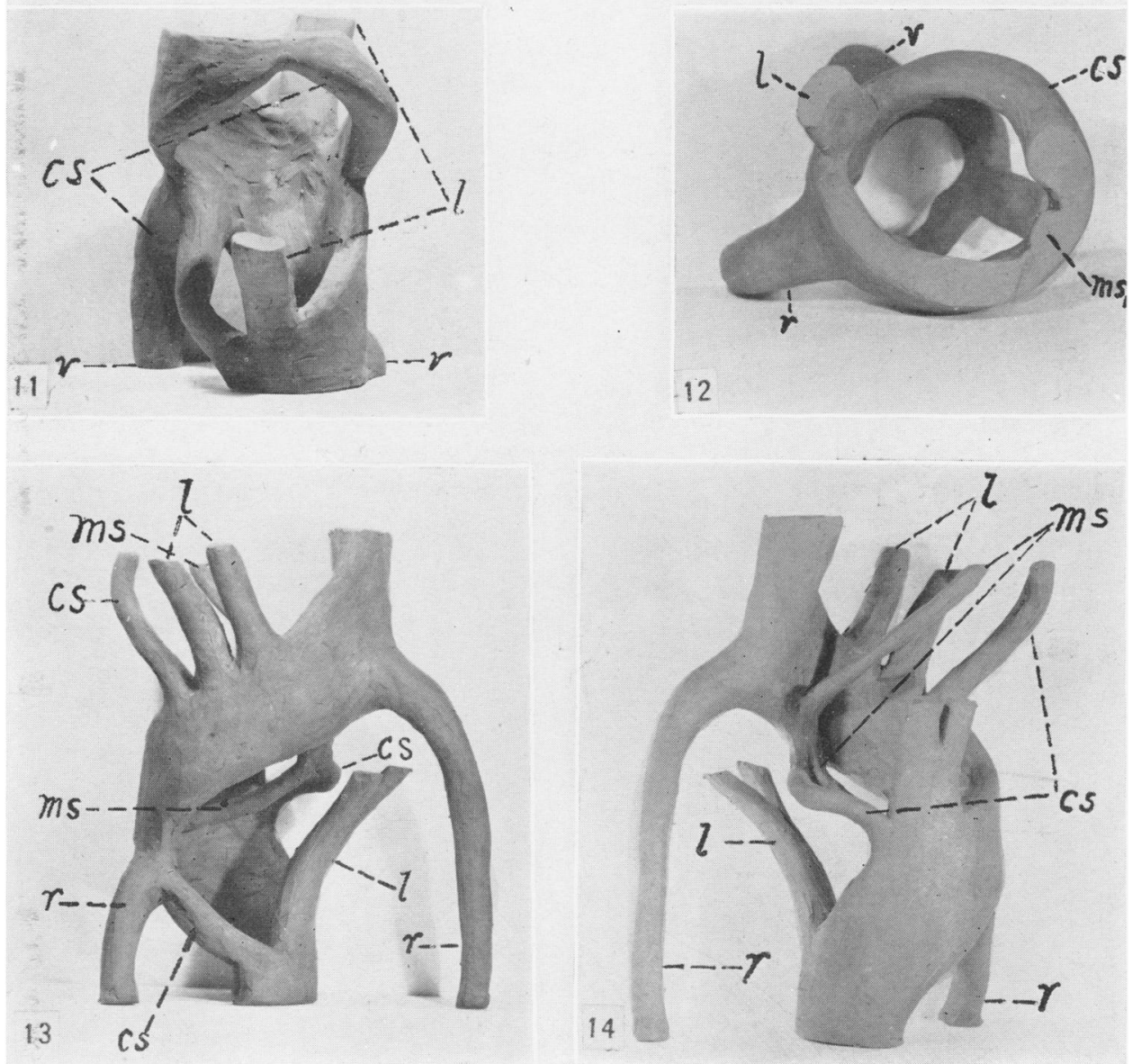

\section{BLOMQUIST on ANGIOPTERIS}

This content downloaded from 080.082.077.083 on February 19, 2018 19:31:13 PM All use subject to University of Chicago Press Terms and Conditions (http://www.journals.uchicago.edu/t-and-c). 

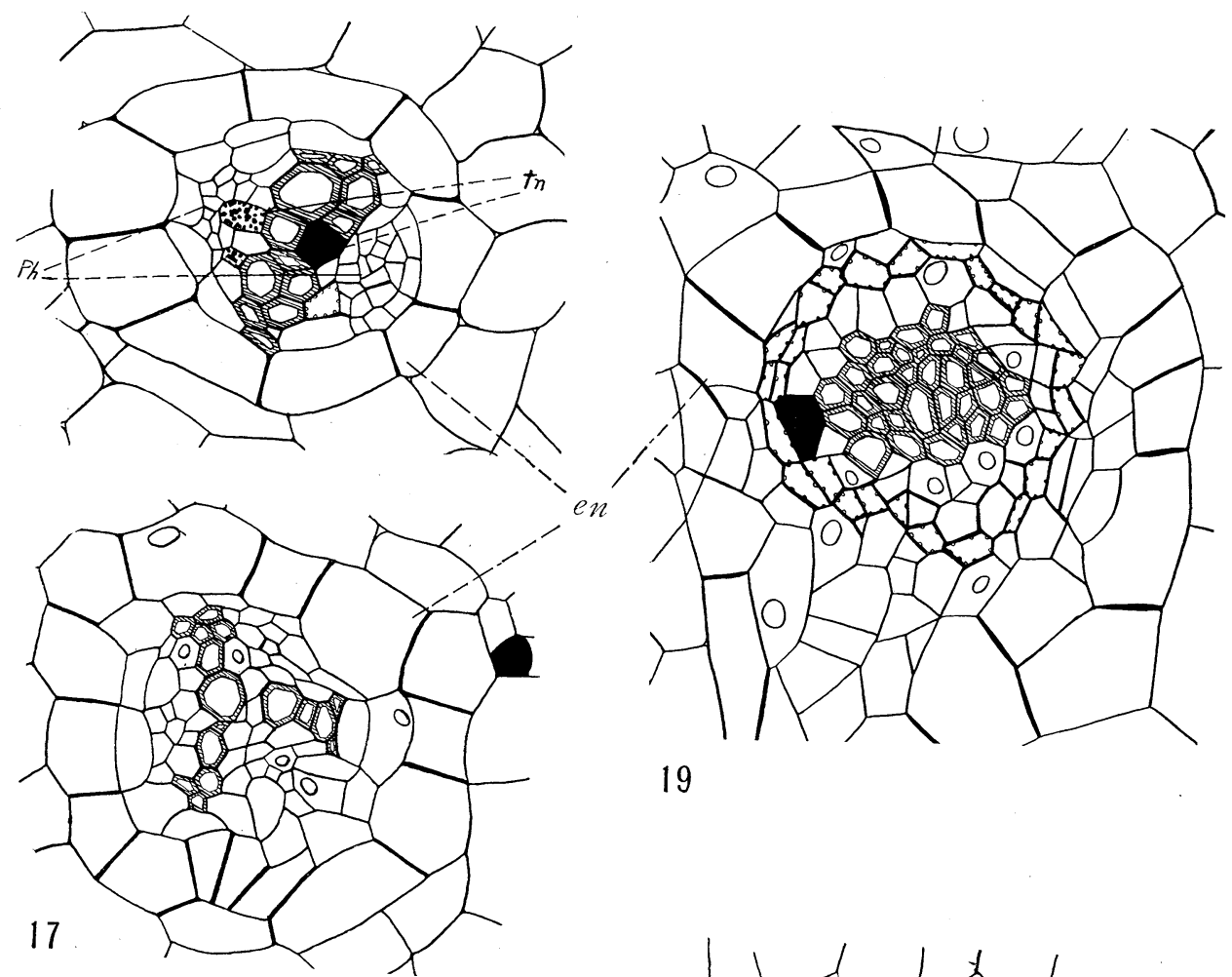

19
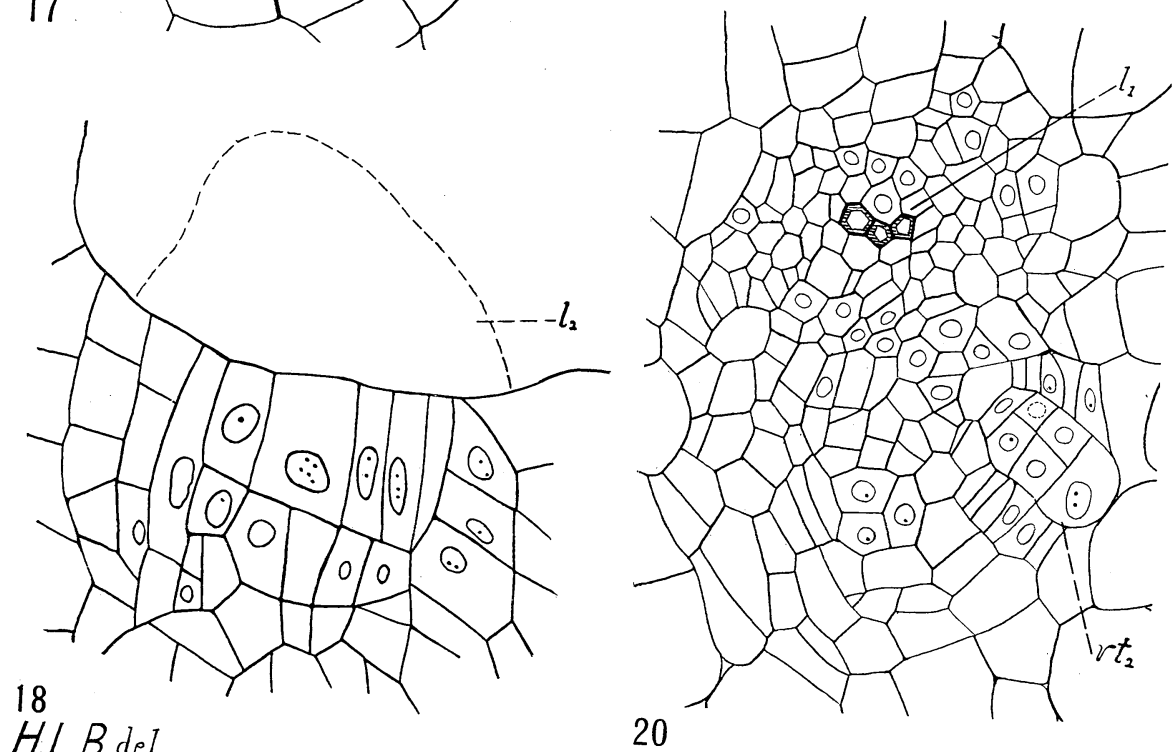

H.L.B.del

BLOMQUIST on ANGIOPTERIS 


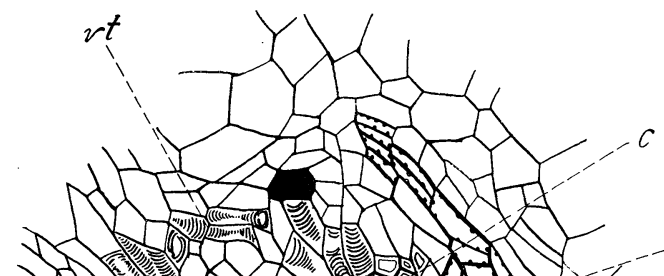
-ph 23
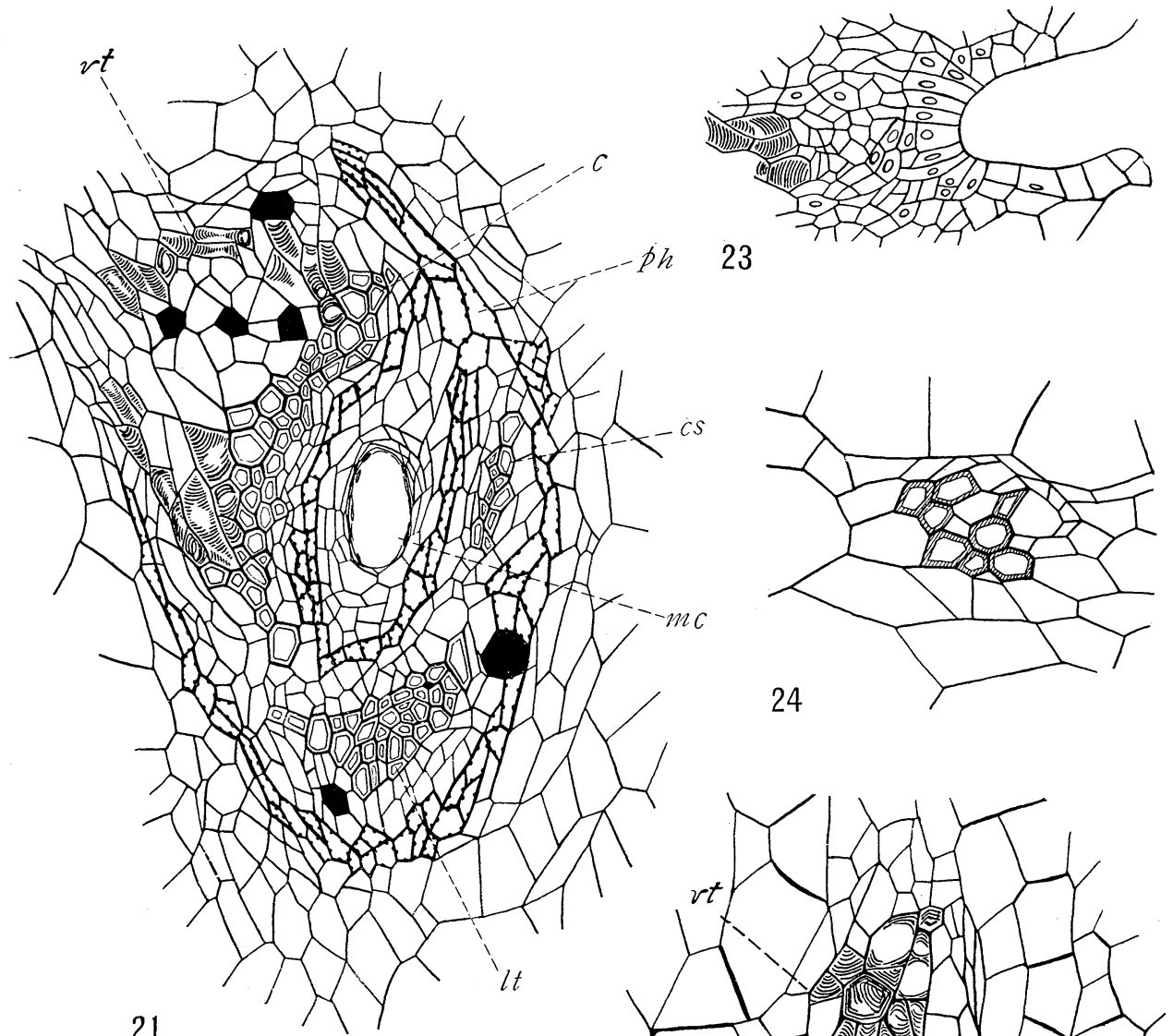

21
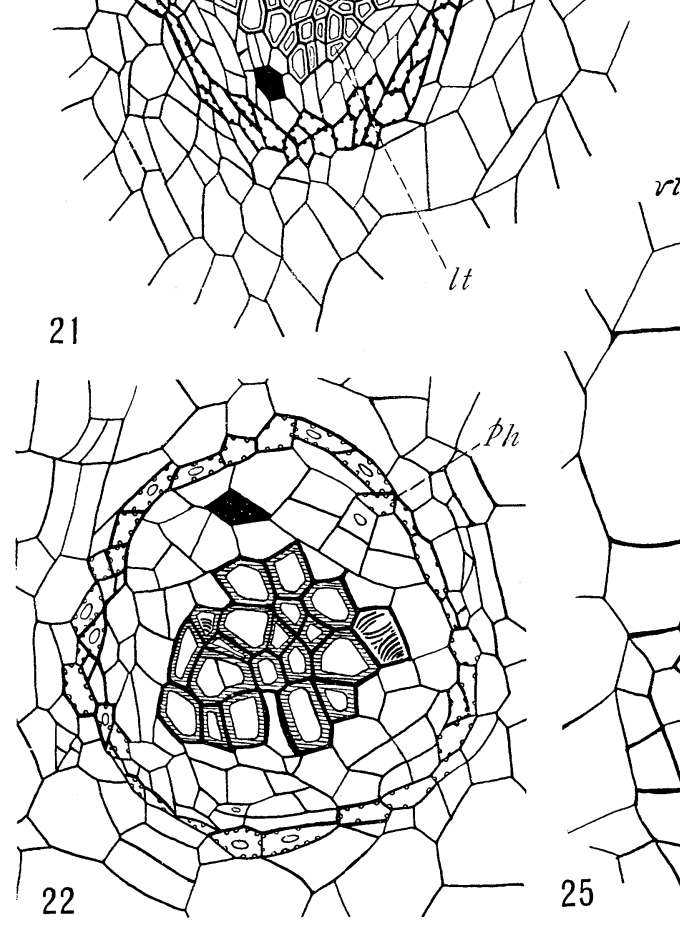

25

H.L.B. del

BLOMQUIST on ANGIOPTERIS 

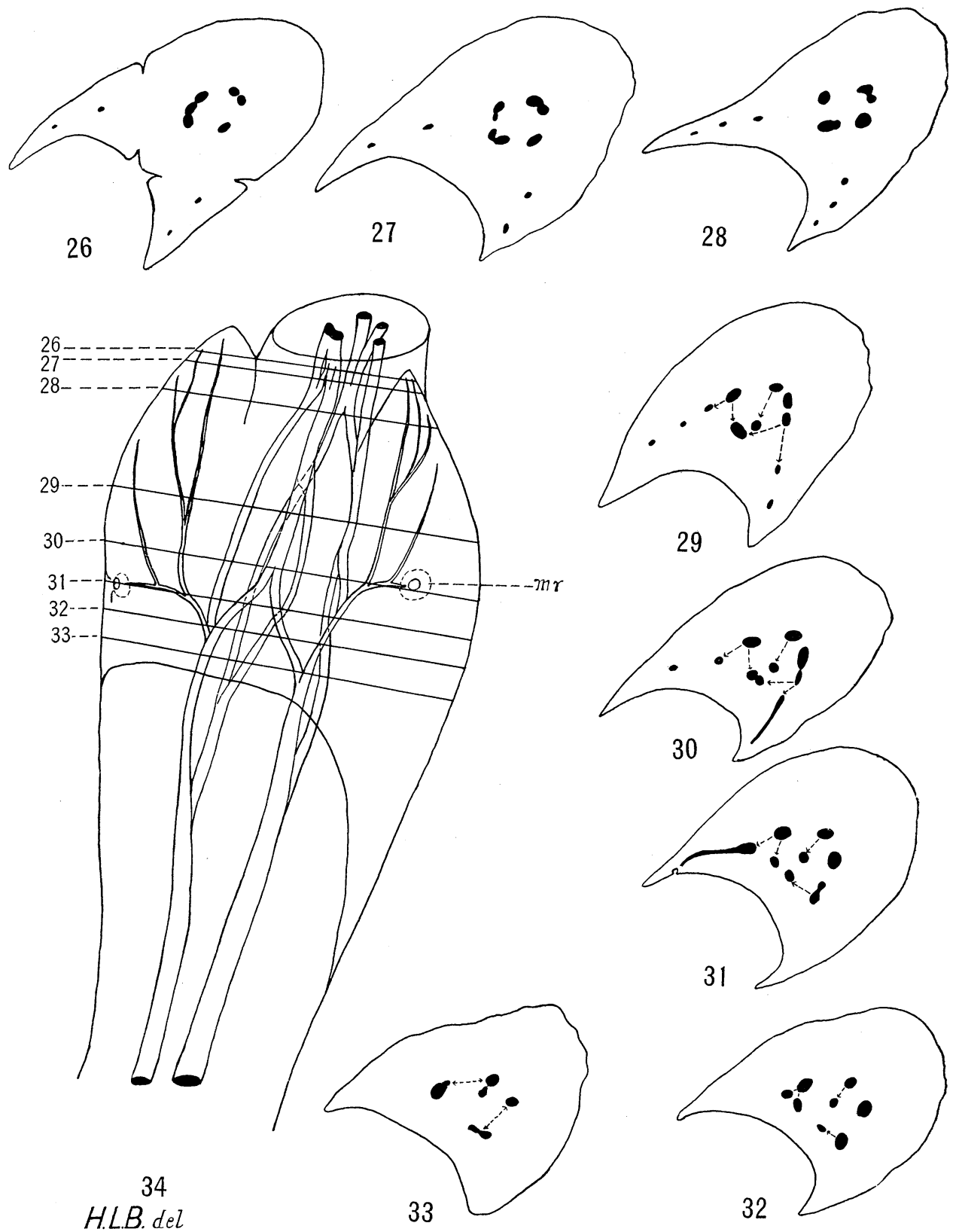

BLOMQUIST on ANGIOPTERIS

This content downloaded from 080.082.077.083 on February 19, 2018 19:31:13 PM All use subject to University of Chicago Press Terms and Conditions (http://www.journals.uchicago.edu/t-and-c). 
9. Gwynne-Vaughan, D. T., On the anatomy of Archangiopteris Henryi and other Marattiaceae. Ann. Botany 19:259-27I. I905.

ro. Holle, J. G., Vegetationsorgane der Marattiaceen. Bot. Zeit. 34: 2 I 5. I876. Ir. LAND, W. J. G., The embryology of Angiopteris evecta (unpublished).

12. Shove, Miss R. F., On the structure of the stem of Angiopteris evecta. Ann. Botany 14:497-525. pls. 28, 29. I900.

13. West, C. A., A contribution to the study of the Marattiaceae. Ann. Botany 3I:3I6-4I4. I9I7.

\section{EXPLANATION OF PLATES V-VIII PLATE $V$}

FIG. 9.-Model of stelar structure represented in fig. 3: $r_{\mathrm{x}}, r_{2}, r_{3}$, first, second, and third root steles; $l_{\mathrm{r}}, l_{2}, l_{3}$, first, second, and third leaf traces; $c s$, commissural strand; $l g$, leaf gap.

FIG. Io.--Same model viewed from above.

FIG. I I.-Model of stelar structure represented in diagram in fig. 4.

FIG. I2.- Same model viewed from above: $m s_{\mathrm{r}}$, first medullary strand.

FIG. I3.- Model of stelar arrangement represented in fig. 5 ; abbreviations same as above.

FIG. I4.- Same model viewed from opposite side.

FIG. I 5.-Same model viewed from above.

\section{PLATE VI}

FIG. I6.-Detail of a diarch primary root: en, endodermis; $p h$, phloem; tn, tannin cell; $p c$, pericycle; $\times 330$.

FIG. I7.-Detail of triarch primary root; $\times 330$.

FIG. I8.-Apical cell at stem tip: $l_{2}$, second leaf; $\times 330$.

FIG. I9.-Detail of transition region; $\times 330$.

FIG. 20.- Section of sporeling: $r t_{2}$, origin of second root; $l_{\mathrm{r}}$, first leaf trace; $\times 330$.

\section{PLATE VII}

FIG. 21.-Detail of central region on level of outgoing of fourth leaf trace: $c$, central strand; $r t_{5}$, fifth root stele; $c s$, commissural strand; $p h$, phloem; $m c$, mucilage canal; $\times$ I 70 .

FIG. 22.-Detail of medullary strand: $p h$, phloem; $\times 330$.

FIG. 23.-Meristematic region terminating main stipular strand; $X_{1} 80$.

FIG. 24.-Detail of stipular strand; $\times 330$.

FIG. 25.-Detail of stele above transition region showing medullated condition; $r t^{2}$, second root trace; $\times 330$.

\section{PLATE VIII}

FIGS. 26-33.-Diagrams of sections of stipular region from advanced stage showing arrangement and inter-relation of vascular strands; $\times 8$.

FIG. 34--Reconstruction of sections: $m r$, meristematic region of stipule; reconstruction is slightly larger than sections to show better the courses of strands. 